\title{
Prevalence of Helminths in Wild Asian Elephant and Indian Rhinoceros in Chitwan and Bardia National Park, Nepal
}

\author{
M. K. Shahi ${ }^{1}$ and K. P. Gairhe*2 \\ ${ }^{1}$ Himalayan College of Agricultural Sciences and Technology, Kathmandu \\ ${ }^{2}$ Chitwan National Park, Sauraha, Chitawan, Nepal \\ *Corresponding author: kamalgairhe@,hotmail.com
}

\begin{abstract}
The Nepalese elephant (Elephas maximus maximus) and rhinoceros (Rhinoceros unicornis), are an important part of Nepal's heritage, culture and wildlife conservation. Despite its importance, not much is known about the helminth parasites that affect elephant and rhinoceros. This study investigates the prevalence of helminth parasites in wild Asian Elephant and wild Indian Rhinoceros.A study was conducted from November 2011 to April 2012 to screen helminth parasites of wild asian elephant and wild Indian Rhinoceros at Chitwan and Bardia National Park of Nepal. Total of 80 samples, 40 each taken from the Wild Asian Elephants and Indian Rhinoceros. The study showed $88.75 \%$ overall prevalence of helminthes. The prevalence in Wild Asian Elephant and Indian Rhinoceros was $95 \%$ and $82.5 \%$ respectively. $97.37 \%$ and $72.73 \%$ infection were mixed infections in elephant and rhinoceros respectively.Among 38 positive samples of the elephant of CNP and BNP, 9 different types of helminth eggs were found. 15 (39.47\%) were positive for Fasciola Spp. With 450 EPG count, 11 (28.95\%) for Paramphistomum spp. with 600 EPG, 27 (71.05\%) for Schistosoma spp. with 500 EPG, 3 (7.89\%) for Dicrocoelium spp. with 900 EPG, 12 (30.16\%) for Moniezia spp. with 433.3 EPG, 17 (44.74\%) for Oesophagostomum spp. with 1025 EPG, 10 (26.31\%) for Chabartia spp. with 1141.65 EPG, 17 (44.74) for Strongyloides spp. with 15558.335 EPG and 23 (60.53\%) for Strongylus spp. with 1700 EPG. Similarly out of the 33 positive samples of Rhinoceros of CNP and BNP, 8 different types of helminth eggs were found. 11 (33.33\%) were positive for Fasciola Spp. With 558.34 EPG, 10 (30.30\%) for Paramphistomum spp. with 525 EPG, 7 (21.21\%) for Schistosoma spp. with 475 EPG, 4 (12.12\%) for Moniezia spp. with 650 EPG, 6 (18.18\%) for Strongyloides spp. with 1466.67 EPG, 4 (12.12\%) for Strongylus spp. with 1625 EPG, 9 (27.27\%) for Toxocara spp. with 699.98 EPG and 20 (60.61\%) for Trychostrongylus spp. with 1149.98 were found to be positive.
\end{abstract}

Keywords: Wild Asian Elephant, Wild Indian Rhinoceros, Helminths, Qualitative and Quantitative Examination

\section{INTRODUCTION}

Nepal is remarkable for an abundance and variety of wildlife which have been famous throughout the world for their uniqueness, gameness, strength, agility and beauty. The mammals of Nepal have intrinsic and biological value. The study of ecology, behavior and health of mammals in nature and captivity can be a great tool in their preservation. Many pristine forms are now verging towards extinction (Shrestha, 1997). The need of wildlife habitat improvement, 
health improvement, preservation of biological diversity, protection of natural environment and monitoring pollution are the fundamental of wildlife conservation.

The Asian Elephant is an endangered species. Although there are few accurate data on historical population size, from what is known about trend of habitat loss/degradation and other threats including poaching, disease condition, an overall population decline of at least of at least $50 \%$ over the three generation time (estimated to be 20-25 years) seems realist. The western populations (Elephas maximus asurus) were probably extinct by $100 \mathrm{BC}$ and the main Chinese population disappeared sometime after $14^{\text {th }}$ century B.C. (IUCN, 1986).

With a few notable exceptions, population of Asian elephant and rhino over the world have experienced major declines over the past few decades as a result of habitat loss, fragmentation and poaching. Large animal like elephant and rhino and elephants are wide ranging and require extensive areas to support viable population. It is possible that rhino and elephant populations in several of Asia's relatively small protected areas have reached caring capacity and the areas have inadequate ecological resources to support larger populations (WWF, 2011).

In Nepal, Elephants were once widespread in the low land terai, but now restricted too, few protected areas along the border with India: CNP, Parsa Wildlife Reserve, BNP and Suklaphanta Wildlife Reserve and their environs. Greater one horned rhinoceros is also one of the IUCN red listed threatened species (Talukdar, 2008). The populations are increasing overall due to strict protection especially in India. However some populations are decreasing, especially in Nepal and parts of northeastern India. Currently, the Indian rhinoceros exist in a few small sub-populations in West Bangal, Uttar Pradesh and Aasam of India and in three protected areas of Nepal. In late 1960 an estimated 65 Indian rhinoceros survived in Nepal, but due to increased conservation efforts, the total population was up to 612 in 2000. A total of at least 91 animals were poached in 2000-2003 and since 2000, numbers have decline. In CNP, the number of individuals has declined 544 individuals in 2000 to 372 individuals in 2005, the decreased being due to increased pouching following political instability in Nepal and habitat changes. In BNP reintroduced rhinos were approximately 40 individuals in 1997 and 35 animals in 2007 while in suklaphanta Wildlife Reserve the re-introduced population is only six individuals (Martin, 2006 cited by Sapkota, 2009). Recent study found population of the rhino 527 (99 more than it was counted in 2008) at CNP and BNP (DNPWC 2011).

Elephant and Rhino are possibly the most well known member of the animal kingdom. The enormous size, unusual anatomy and longevity of elephants have fascinated humans for millennia. Elephant are mainly raised in wildlife reserves for security purpose and patrolling. Most free living organism harbors parasites of several species which can adversely affect host health, fecundity and foraging and may also modify host behavior to fascinate parasites transmission (Hamilton et.al., 1996). Asian Elephant Elephas maximus are susceptible to gastrointestinal parasitic infection in wild and in captivity are often confined to small enclosure and/or maintained in isolation (Vanitha et.al., 2011) 


\section{MATERIALS AND METHODS}

\section{Site of Study}

The study areas were CNP and BNP. CNP is the first National Park at the terai (Siwalik) of mid Nepal in the south-east part of the Chitwan District, NarayaniZonne. It covers an area of 932 sq. $\mathrm{km}$. The park covers the part of Parsa,Makawanpur, Nawalparasi and Chitwan districts, encloses RaptiVally, Churea hill, Ox-bow Lake, rivers like Narayani, Rapti, Reu and Sal dominated forest, grassland with the flood plain. BNP located at the Bardia district of Midwestern Nepal in the bank of KarnaliRiver and covers an area of 969 sq.km and established at 1975. It is low land park at Terai (Siwalik) region. Population of elephant and rhinoceros in both National Parks are 527 (DNPWC 2011) and 278 (ECAPN-2008).

\section{Sampling of Animal}

Opportunistic fresh fecal samples were taken. The samples were collected on the plastic bags. Ice box and 3\% formalin are used for the transportation of the samples from national Park to the Laboratory. The examined samples of CNP were collected from November $1^{\text {st }} 2011$ to January $15^{\text {th }}$ 2012. Similarly examined sample of BNP were collected from January $16^{\text {th }}$ to march $14^{\text {th }}$ 2012. Numbers of sample taken from National Parks are shown in table 1. Due to the risk of the wild animal during sample collection, captive elephant was used for travelling within the National Park.

Table 1: Numbers of sample from the different sites

\begin{tabular}{|l|l|l|l|}
\hline Wild Animal & CNP & BNP & Total \\
\hline Elephant & 20 & 20 & 40 \\
\hline Rhinoceros & 20 & 20 & 40 \\
\hline Total & 40 & 40 & 80 \\
\hline
\end{tabular}

\section{Identification of the Sample}

The detail qualitative coprological parasitic investigation was assessed through direct microscopic examination and sedimentation floatation method as per Soulsby (1978). Egg and larvae identifications were made as per the atlas of Soulsby (1978). Qualitative examination was done by direct smear method, Sedimentation method and differential floatation Method.

Quantitative investigation was done by egg per gram count (EPG) to know the number of parasite eggs in the animal by using McMaster counting. 


\section{RESULT AND DISCUSSION}

\section{Result}

The study showed the overall prevalence ofhelminthes to be $88.75 \%$. The prevalence in wild Asian Elephant and Indian Rhinoceros was 95\% and 82.5\% respectively. 97.37 and $72.73 \%$ infection were mixed infections in elephant and rhinoceros respectively. Location wise prevalence in elephants of CNP and Elephant of BNP, Rhinoceros of CNP and rhinoceros of BNP were 95\%, 95\%, 75\% and 90\% respectively. The detail of helminthes in elephant and rhinoceros are illustrated in table 2 .

Table 2. Overall Prevalence of helminthes parasites

\begin{tabular}{|l|l|l|l|l|l|}
\hline \multirow{2}{*}{} & \multicolumn{2}{|c|}{ CNP } & \multicolumn{2}{c|}{ Total } \\
\cline { 2 - 5 } & Elephant & Rhinoceros & Elephant & Rhinoceros & \\
\hline Total & 20 & 20 & 20 & 20 & 80 \\
\hline Positive & $19(95 \%)$ & $15(75 \%)$ & $19(95 \%)$ & $18(90 \%)$ & $71(88.75 \%)$ \\
\hline
\end{tabular}

\section{Species of Parasites Identified in Elephant and Rhinoceros of CNP and BNP}

\section{Species of Helminthes in Elephant}

Among 40 fecal samples of the elephants of CNP and BNP, 38 (95\%) sample were positive and 9 different types of helminthes egg were identified. Among 38 positive samples of the elephant of CNP and BNP, 9 different types of helminth eggs were found. 15 (39.47\%) were positive for Fasciola Spp. With 450 EPG count, 11 (28.95\%) for Paramphistomum spp. with 600 EPG, 27 (71.05\%) for Schistosoma spp. with 500 EPG, 3 (7.89\%) for Dicrocoelium spp. with 900 EPG, 12 (30.16\%) for Moniezia spp. with 433.3 EPG, 17 (44.74\%) for Oesophagostomum spp. with 1025 EPG, 10 (26.31\%) for Chabartia spp. with 1141.65 EPG, 17 (44.74) for Strongyloides spp. with 15558.33 EPG and 23 (60.53\%) for Strongylus spp. with 1700 EPG. The detail of parasites and their prevalence are illustrated in Figure 1.Dicroclium spp. was not found in BNP elephant.

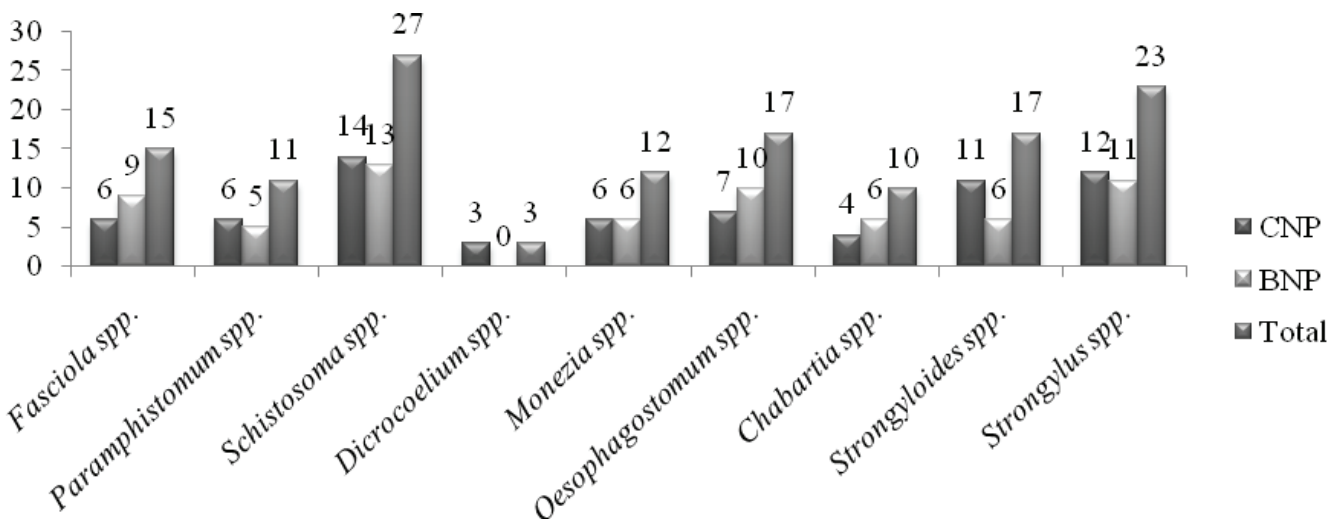

Figure 1: Number of samples positive for helminth in elephant with percentage out of total positive samples 


\section{Species of Helminthes in Rhiniceros}

sample of the CNP. The detail of parasites and their prevalence are illustrated in figure 2. Out of 40 fecal samples of the rhinocerous of CNP and BNP, 33 (82.5\%) were positive and 8 EPG, 6 (18.18\%) for Strongyloides spp. with 1466.67 EPG, 4 (12.12\%) for Strongylus spp. different types of helminth eggs were found. 11 (33.33\%) were positive for Fasciola Spp. With 558.34 EPG, 10 (30.30\%) for Paramphistomum spp. with 525 EPG, 7 (21.21\%) for Schistosoma spp. with 475 EPG, 4 (12.12\%) for Moniezia spp. with 650 with 1625 EPG, 9 (27.27\%) for Toxocara spp. with $699.98 \mathrm{EPG}$ and 20 (60.61\%) for Trychostrongylus spp. with 1149.98 were found to be positive. But Monezi spp. and Strogylus spp. were not found in rhino sample of BNP. Similarly Strongyloides spp was not found in

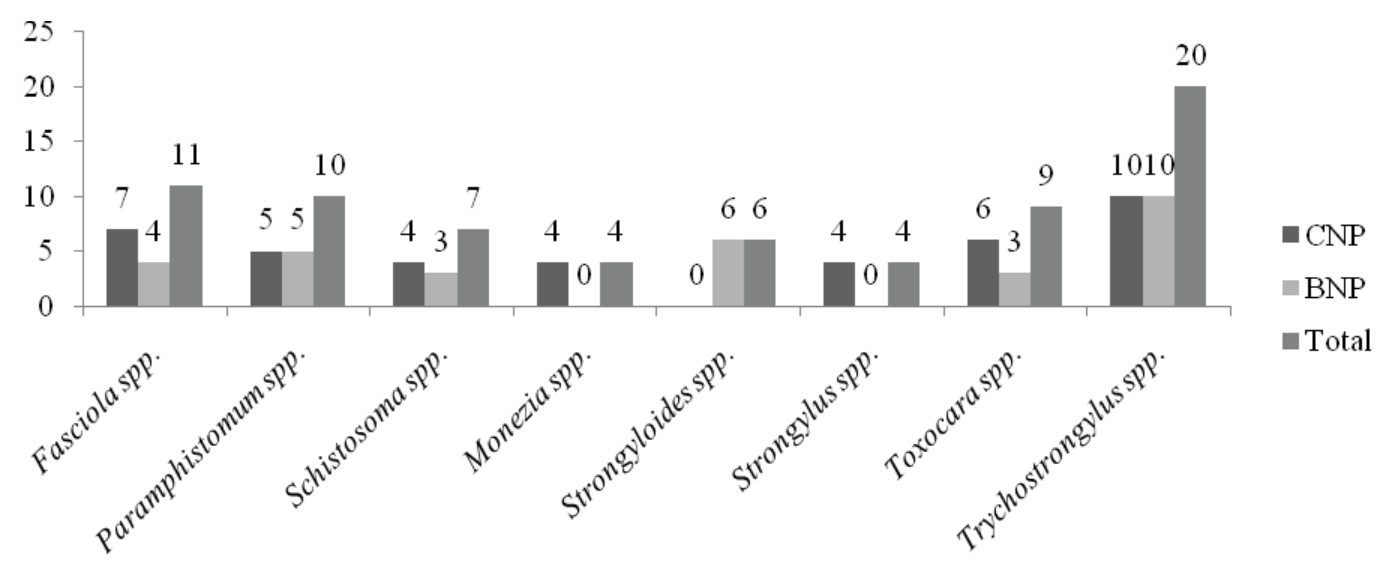

Figure 2: Number of samples positive for helminth in Rhinoceros with percentage out of total positive samples

\section{Prevalence Based on the Spectrum of Helminth Infections}

\section{Wild Asian Elephant}

Out of the 38 positive fecal samples of the elephant, $37(97.37 \%)$ reveled mixed parasitic infection and 1 sample (2.63\%) had single infection (figure 3 ) 


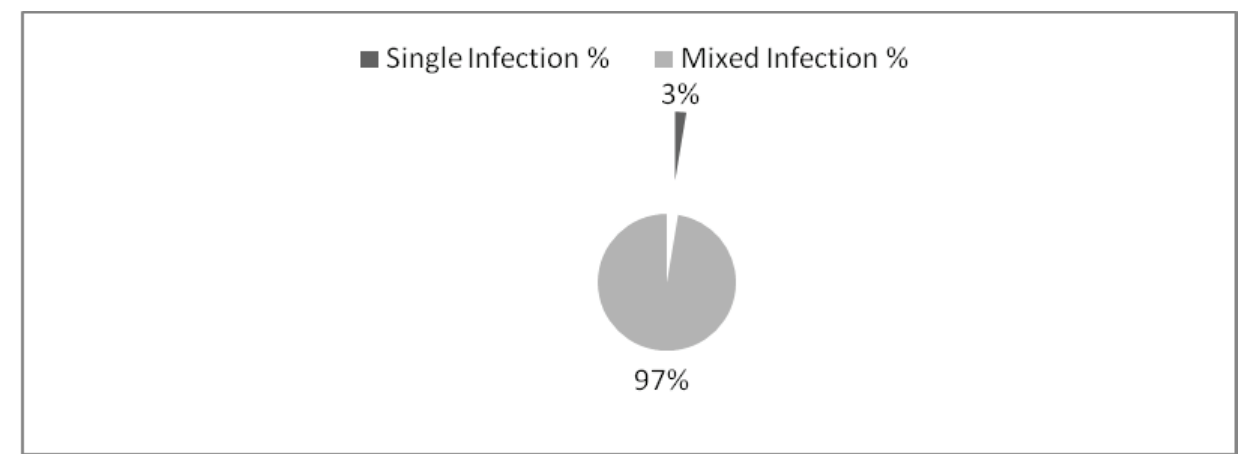

Figure 3: Prevalence based on the spectrum of helminth infection in elephant

\section{Indian Rhinoceros}

Out of the 33 positive fecal samples of the elephant, $24(27.27 \%)$ reveled mixed parasitic infection and 9 samples $(72.73 \%)$ had single infection. The photos of parasite eggs are given in Annex X.

\section{Prevalence Based on Classes of Helminth Parasites}

\section{Wild Asian Elephant}

Out of the 38 positive fecal samples from elephants of the both national parks, 34 (41.46\%) sample have trematodes infection, $36(43.90 \%)$ samples had nematode infection, 12 (14.63\%) samples had cestodes infection.

\section{Indian Rhinoceros}

Out of the 33 positive fecal samples from elephants of the both national parks, $23(44.23 \%)$ sample have Trematodes infection, 25 (48.08\%) samples had nematode infection, 4 (7.69\%) samples had cestodes infection.

\section{Egg per gram (EPG) Count}

\section{Wild Asian Elephant}

Out of the 40 fecal samples of the elephant from both National Parks, 20 (11from CNP and 9 from BNP) samples were analyzed randomly for EPG. The results obtained are presented on figure 4 . 


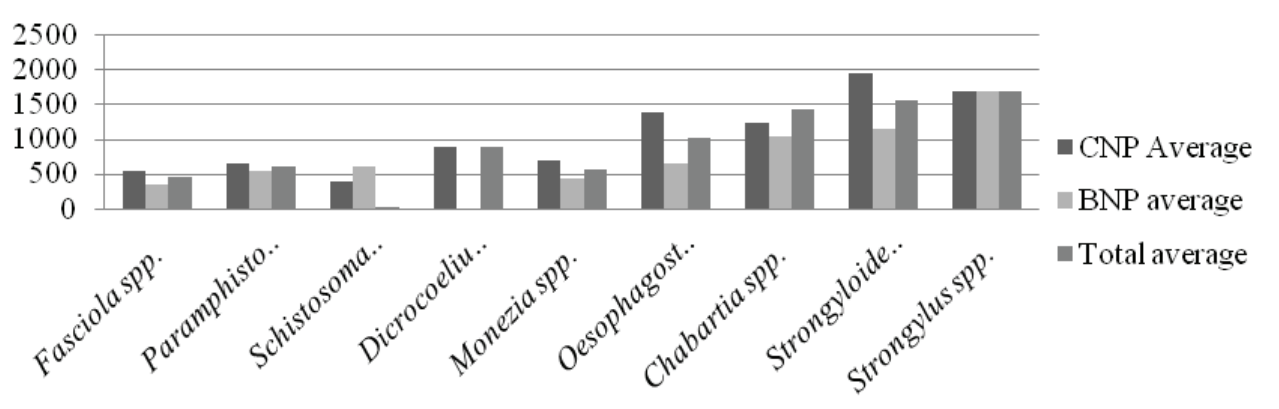

Figure 4: EPG count of different helminth parasites of wild Asian Elephant of CNP and BNP

\section{Wild Indian Rhinoceros}

Out of the 40 fecal samples of the rhinoceros from both National Parks, 19 (10 from CNP and 9 from BNP) samples were analyzed randomly for EPG. The results obtained are presented on figure 5 .

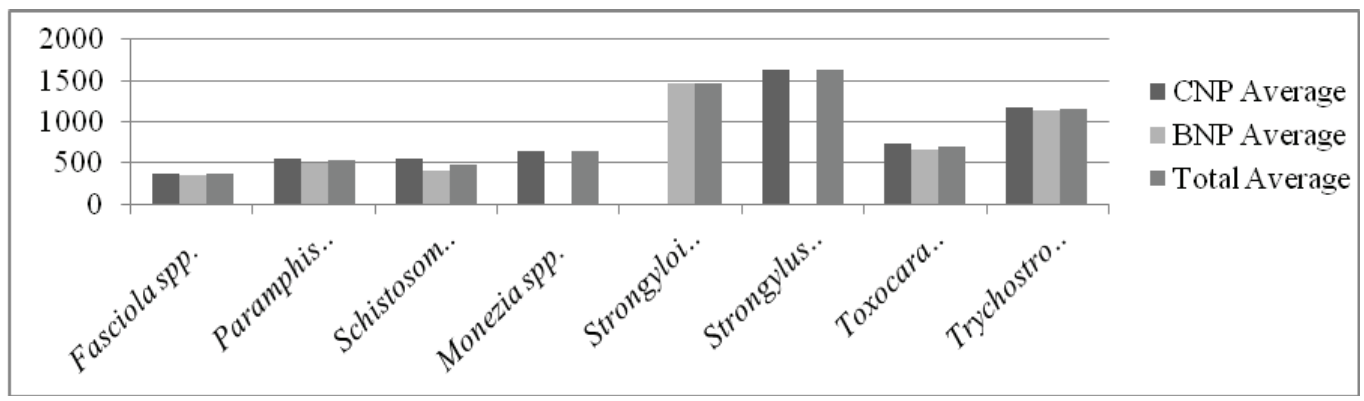

Figure 5: EPG count of different helminth parasites of wild Indian Rhinoceros of CNP and BNP

\section{DISCUSSION}

Karki and Manandhar (2007) reported 100\% prevalence of the internal parasites in captive elephant of the National Park and Wildlife reserve but this study in wild elephants showed lower prevalence of internal parasites than their study. It may be due to the lower sample size and seasonal variation. They also reported that in Captive elephant of Nepal 30\% Fasciolajacksoni, 10\% Paramphistomum, 75\% Oesophagostomum, 90\% Schistosomoses, 18\% Chabertia, 5\% Dicrocielium, 5\% Moniezia species prevalence. The infection of Oesophagostomum, Schistosomoses and Chabertia species were found high but infection of Fasciola, Paramphistomum, Dicrocielium and Moniezia species were found less than this study. Also parasites like Strongyloides and Strongylus species were not reported (Karki and Manandhar 2007) in captive elephant. That might be due to management practice of elephant and other.

Location wise samples showed that samples from CNP were for Fasciola, Paramphistomum and Oesophagostomum spps. (Karki and Manandhar 2007). But in our finding 6 more parasites are reported in CNP elephants, they are Schistosoma, Dicrocielium, Moniezia, Chabertia, 
Strongyloides and Strongylus species. That may be due to the wild state of elephant and great sample size.

In Feburary 94 proglottides of Anoplocephala gigantean were reported in the feces of rhino of Nepal (Rietschel, 2000) but this species was not observed in this study.Li. et.al., (1993) recovered Choniangiumepistomum, Murshidiafalcifera, M. murshida, Chabartia spp.from Elephas maximus in China. Except Chabartia spp. other parasites are not reported in this study that might be due to geographic and climatic variation, type of methodology adopted etc.

DNPWC, Annual Report 2011 shows the death of 18 rhino in a period of 10 month (2067-05-02 to 2068-3-30) in Nepal, out of which 14 (77.78\%) death were natural. Thus, this death may indicate that wild rhinoceros are also dying from disease condition, which might be due to the parasitic Load. Therefore extensive research of the health problem including helminth load should be carriedout along with the treatment protocol of wildlife.

Dung samples collected from 44 and 55 elephants during 2000 and 2002 respectively and examined for the presence of helminths ova. Of the 99 elephants, 17 (17.17\%) were positive for helminthes. The incidence of helminth infection is decreased from $22.73 \%$ in 2000 to $12.73 \%$ in 2002. Among the positive dung samples, 10 (10.10\%) had Strongylidae and 7 (7.07\%) had Digeneaspp. (Saseendran, et.al., 2004). This study shows the lower prevalence of helminth than our finding. That might be due to the low incidence of helminth infection among captive elephants in the studied area may be captive elephant.

Qufiloniatravancra and Bathmostomum sangeri were reported for the first time in Malasysia (Cheah et.al., 1993) but these species are not reported in Nepal. This may be due to the lack of research seasonally and periodically.Chakraborty and Ishlam, 1993 recorded Kilulumagoodeyi, Charbertia spp., Necator ammericans, Bonostomum spp., Paramphistomum spp., Anoplocephala spp. and hydaitid cyst. Some of these parasites are not found in our study.

Of the 84 fresh rhino fecal samples, avoided at different dung heap by individual rhinoceros $61.90 \%$ was positive and different parasites reported were of genera Paramphistomum (39), Strongylus (17) and Anoplocephala (2) (Chakraborty and Islam, 1993). This report is lower than out finding that might be due to ecology, climate or season etc.

The result showed that the Fasciolidae were present in 25\% of Rhinoceroses, Oxyuris spp. were present in $25 \%$ of rhinoceros, the Paramphistomum were present in $64.86 \%$ of elephants and the Acaridae were present in $2.7 \%$ of elephants (Muryani et.al., 2008). Fasciolidae infection is similar to our study but prevalence of the Paramphistomum in elephants higher than the study, which may be due to the climatic variation, host-species difference etc.Kashid et.al., 2003 studied that fecal of various species of wild and zoo animal for the presence of gastrointestinal helminthes and concluded that there are many helminth parasites that have common host or might have public significance. 
There are so many parasites that are not reported in Indian Rhinoceros of Nepal but reported once from other species of rhinos are: from the stomach of the black Rhinoceros, from the Umfolozi Game Reserve, South Africa (Gibbons et.al., 1996), Kilulumagoodeyi, Charbatia spp., Necator ammericans, Bonostomum spp., Paramphistomum spp., and Anoplocephala Spp., (Chakarborty and Ishlam 1995). Nematode Specimens collected from feces of the Indian one horn Rhinoceros (Rhinoceros unicornis) in the Alipori Zoological Garden, Calcutta, India are diagnosed as a new species under the genus Probstmayria and named as Probstmayria bangaliansis. These all Parasites not reported in Nepal's Indian rhino but further studyand larvae culture for the nematode identification is needed.

\section{CONCLUSION}

Parasitic infection decreases the production and productivity in the animals mainly in the reduction of the body weight or failure to gain weight or even increase the mortality in acute cases. Being the both Asian elephant and Indian rhinoceros IUCN red listed wildlife, conservation of those species should be our national objective. Poaching and habitat loss and climate changes are the main causes of population decline but emphasis should also be given to wildlife health aspect which may contribute to save the species by intervention on disease ecology.

A coprological study was conducted to determine the prevalence of helminth parasites in the wild Asian elephant and Indian rhinoceros of CNP and BNP, Nepal. The study showed the overall prevalence of helminth to be $88.75 \%$. The prevalence in Asian elephant and Indian rhinoceros was $95 \%$ and $82.5 \%$ respectively. The mixed infection found in elephant and rhinoceros were $97.37 \%$ and $72.73 \%$ was to be found among the 38 and 33 out of the 40 samples respectively. Thus we can conclude that there is a high load of the helminth parasites in wild elephant and rhinoceros, which also may be the causes of death. So, development of treatment protocols for wildlife is essential for wildlife conservation.

\section{RECOMMENDATION}

This study revealed many parasites of zoonotic importance from wild animals which indicates human and animal populations of the buffer zone area is in the risk of parasitic infestation. We recommend to further conduct extensive research year-round to monitor the prevalence of helminthsto explore epidemiology and prevalence of other infectious transmissible diseases in livestock and wildlife.For the wildlife health problem, specific policy should be formulated to cover overall area of the wildlife including veterinary sectors. Research on anthelmintic property of herbs and shrubs should be prioristized. Also, we suggest performing regular deworming programme of livestock in buffer zone and captive elephant.

\section{ACKNOWLEDGEMENT}

I would like to express my sincere indebtedness to advisory committee and staff of the Department of National Park and Wildlife Conservation (DNPWC), Babarmahal Kathmandu, for granting 


\section{REFERENCES}

ARSG, 2007.Asian Rhino Project 2007. (Online), Available: www.savetherhino.org/asia/, (accessed janurary, $2^{\text {nd }} 2012$ ).

Bhatia, B.B., Pathak, K.M.L., Banerjee D.P. 2006. A text book of veterinary parasitology. 2nd ed, kalyani publishers.

Cameron, T.W.M. 1964. Host specificity and evaluation of helminths parasites. Advance in parasitology. 2 pp. 1-34.

Chakraborty, A., Chaudhury, B. 1991. Fasciolajacksoni infection in elephants. In: Proceeding of International Seminar on Veterinary Medicine in Wild and Captive Animals, Bangalore, India, November 8 to $10,1991$.

Chakraborty A. and Islam S. 1993. On KilulumaSkriabin, a genus of Strongylid nematodes parasitic in the African rhinoceros of the Zoological Department. India: Lucknow University, Journal of helminthology, (2)5, pp. 209-236

Chandrasekharan, K., Cheeran, J.V., Nair, K.N.M., Ramanujam, K.N. and Radhakrishnan, K. 1982. Comparative efficacy of 6 anti-helminthics against strongylosis in elephants. Kerala Journal of Veterinary Science, 13, pp. 15-20.

Cheah, T.S., Rajamanickam, C., Ong, B.L., Lazarus, K. 1993. A first record in Malaysia of Quiloniatravancra (Lane, 1914) and Bathmostomums angeri (Cobbold, 1879) in Malaysian elephants (Elephas maximus hirsutus). Tropical Biomedicine, 10, pp. 41-43.

Department of National Park and Wildlife Conservation, 2011. Annual report 2011. DNPWC, Kathmandu, Nepal.

Gibbons, L. M. 1996. Dicerinemaver sterae gen. from the black rhinoceros, Dicerosbicornis bicornis, in souh Africa. In: International institute of parasitology, St. Albans, hert, UK. Helminthol, soc. Wash, pp. 98-104.

Holmes, P.H. 1987. Pathophysiology of parasitic infection. Parasitology, 194, pp. 29-51.

IUCN, 1986. Conservation Monitoring Centre. (online), Available: http://www.iucnredlist.org/detail/, (Accessed January, $3^{\text {rd } 2012)}$

IUCN, 2011. Indian rhinoceros (Rhinoceros unicornis) and Asian elephant (Elephas maximus). (Online), Available: http://www.arkive.org/indian_rhinocerosandAasianelephant/, (Accessed January $2^{\text {nd }}$ 2012).

Joshi, B. R. 1991. Gastrointestinal nematode infection of small ruminants and possible control strategies in the hills and mountains of Nepal. Veterinary review, 13, pp.1-5.

Karki, K. and Manandhar, P. 2007. Incidence of gastrointestinal helminths in captive elephants in wildlife reserves of Nepal. (online) Available: http://www.scribd.com/doc/3722517/Gastrointestinal-Parasites-ofelephant?autodown=doc (Accessed 22 Jan 2012).

Kashid, K.P., Shrikhande, G.B. and Bhojne, G.R. 2003. Incidence of gastro-intestinal helminths in captive wild animals at different locations. Zoos' Print Journal, 18, pp. 1053-1054.

Kharchenko, V.A. and Marunchin, A. A. 1992. Helminths of mammals in the Kiev zoological park. VestnikZoologii, 3, pp. 61-63.

Li, C.X., Rong, Y.M. and Xie, Q.P. 1993. A study of helminth parasites of elephants (Elephas maximus). Chinese Journal of Zoology, 28, pp. 43-44.

Muryani, R., Tiuria and Agil, M. 2008. Helminths parasite at feces of Sumatran rhinoceros (Dicerorhinussumtrensis) and sumatran elephant (Elephas maximus surnatranus) in Way Kambas National Park. Lampung (semi insitu), Bogor Agricultural University. 
Rietschel, W. 2000. Case reports and veterinary aspects of breeding the Indian rhino (Rhinoceros unicornis) at Stuttgart zoo. In: European Association of zoo and wild life veterinarians (EAZWV), third scientific meeting, May 31th - June $4^{\text {th }}$, 2002, Paris, France, p. 198.

Sapkota, R.C. 2009, Prevalence of Helminths in Deer of Central Zoo, Godawari Deer research centre and Bankali forest. Mini-thesis, HICAST, Purbanchal University

Saseendran, P.C., Rajendran, S., Subramanian, H., Sasikumar, M., Vivek, G. and Anil, K.S. 2004. Incidence of helminthic infection among annually dewormed captive elephants. Zoos' Print Journal, 19, pp. 1422.

Shrestha, T. K. 1997. Mammals of Nepal. $1^{\text {st }}$ ed, Kathmandu, Nepal, pp. 222-228, 257-260.

Soulsby, E.J.L. 1978. Helminths, Arthrpods and Protozoa of Domesticated Animals. The English Language Book Society and Bailliere, $6^{\text {th }}$ edn, Tindall and Cassell Ltd., pp. 207-218.

Talukdar, B.K., Emslie, R., Bist, S.S., Choudhury, A., Ellis, S., Bonal, B.S., Malakar, M.C., Talukdar, B.N. and Barua, M. 2008. Rhinoceros unicornis In: IUCN 2011. IUCN Red List of Threatened Species, Version 2011.2, www.iucnredlist.org, (Accessed 14 June 2012).

Vanitha, V., L. Thiyagesan and Baskaran 2011. Prevalence of intestinal parasites among captive Asian elephants Elephas maximus; effect of the season, host demography and managemental systems in Tamil Nadu, India. Journal of ThereatenedTexa, 3 (2), pp. 1527-1534.

WWF, 2011. Conservation Monitor Centre. (online), Available: http://www.panda.org/about_wwf/ (Accessed January, $3^{\text {rd } 2012) . ~}$

\section{Annexes}

Annex I: Population of the Asian elephant and rhinoceros in CNP and BNP

\begin{tabular}{|c|c|c|c|}
\hline \multirow{2}{*}{} & Rhinoceros & \multicolumn{2}{|c|}{ Elephant } \\
\cline { 3 - 3 } & & Captive & Wild (overall) \\
\hline BNP & 24 & 21 & $107-145$ \\
\hline CNP & 503 & 112 & \\
\hline SOURCE & DNPWC annual report 2011 & ECAPN-2009 & Yonzon- 2008 \\
\hline
\end{tabular}

Annex II: Number of samples from the different sites

\begin{tabular}{|c|c|c|c|}
\hline Species & Chitwan National Park & Bardia National Park & Total \\
\hline Elephant & 20 & 20 & 40 \\
\hline Rhinoceros & 20 & 20 & 40 \\
\hline Total & 40 & 40 & 80 \\
\hline
\end{tabular}


Annex III: Identification of feces of rhinoceros and elephant

\begin{tabular}{|c|c|c|c|}
\hline S.N. & Identification tool & Rhinoceros & Elephant \\
\hline 1 & Color & Generally black and dark green & Dark grey and yellowish \\
\hline 2 & $\begin{array}{l}\text { Site of } \\
\text { defecation }\end{array}$ & $\begin{array}{l}\text { Defecate in the same place by } \\
\text { number of individual }\end{array}$ & Defecate on the walking way \\
\hline 3 & Consistency & $\begin{array}{l}\text { Less fibrous than elephant's } \\
\text { feces }\end{array}$ & More fibrous \\
\hline 4 & Fibers in feces & Thin and short & Thick and long \\
\hline 5 & Foot print & Observe nearby feces & Large \\
\hline 6 & Age difference & $\begin{array}{l}\text { Different size of the stool mass } \\
\text { in a place }\end{array}$ & $\begin{array}{l}\text { Different size of the stool } \\
\text { mass in different place }\end{array}$ \\
\hline 7 & $\begin{array}{l}\text { Time of } \\
\text { defecation }\end{array}$ & $\begin{array}{l}\text { Feces become moist and appear } \\
\text { fresh within } 24 \text { hours }\end{array}$ & $\begin{array}{l}\text { Feces become moist and appear } \\
\text { fresh within } 24 \text { hours }\end{array}$ \\
\hline
\end{tabular}

Annex IV: Number of sample positive for helminth in wild Asian elephant with percentage out of total positive samples

\begin{tabular}{|c|l|c|c|c|c|}
\hline S.N. & \multicolumn{1}{|c|}{ Helminths parasites } & CNP & BNP & Total & $\%$ \\
\hline 1 & Fasciola & 6 & 9 & 15 & 39.47 \\
\hline 2 & Paramphistomum & 6 & 5 & 11 & 28.95 \\
\hline 3 & Schistosoma & 14 & 13 & 27 & 71.05 \\
\hline 4 & Dicrocoelium & 3 & 0 & 3 & 7.89 \\
\hline 5 & Moniezia & 6 & 6 & 12 & 30.16 \\
\hline 6 & Oesophagostomum & 7 & 10 & 17 & 44.74 \\
\hline 7 & Chabertia & 4 & 6 & 10 & 26.31 \\
\hline 8 & Strongyloides & 11 & 6 & 17 & 44.74 \\
\hline 9 & Strongylus & 12 & 11 & 23 & 60.53 \\
\hline
\end{tabular}


Annex V: Number of sample positive for helminth in Indian rhinoceros with percentage out of total positive samples

\begin{tabular}{|c|l|c|c|c|c|}
\hline S.N. & \multicolumn{1}{|c|}{ Helminths parasites } & CNP & BNP & Total & $\%$ \\
\hline 1 & Fasciola spp. & 7 & 4 & 11 & 33.33 \\
\hline 2 & Paramphistomum spp. & 5 & 5 & 10 & 30.30 \\
\hline 3 & Schistosoma spp. & 4 & 3 & 7 & 21.21 \\
\hline 4 & Moniezia spp. & 4 & 0 & 4 & 12.12 \\
\hline 5 & Strongyloides spp. & 0 & 6 & 6 & 18.18 \\
\hline 6 & Strongylus spp. & 4 & 0 & 4 & 12.12 \\
\hline 7 & Toxocara spp. & 6 & 3 & 9 & 27.27 \\
\hline 8 & Trychostrongylus spp. & 10 & 10 & 20 & 60.61 \\
\hline
\end{tabular}

Annex VI: Single and mixed infection in wild Asian elephant and Indian rhino

\begin{tabular}{|l|l|l|l|l|l|l|l|l|}
\hline \multirow{2}{*}{$\begin{array}{l}\text { Type of } \\
\text { infection }\end{array}$} & \multicolumn{4}{|c|}{ Wild Asian elephant } & \multicolumn{4}{c|}{ Wild Indian rhinoceros } \\
\cline { 2 - 10 } & CNP & BNP & Total & $\%$ & CNP & BNP & Total & $\%$ \\
\hline Single & 1 & 0 & 1 & 2.63 & 2 & 7 & 9 & 27.27 \\
\hline Mixed & 18 & 19 & 37 & 97.37 & 13 & 11 & 24 & 72.73 \\
\hline
\end{tabular}

Annex VII: EPG count of different helminths parasites of wild Asian elephant of CNP and BNP

\begin{tabular}{|c|l|c|c|c|}
\hline \multirow{2}{*}{ S.N. } & \multicolumn{1}{|c|}{ Helminth Species } & \multicolumn{3}{c|}{ EPG average } \\
\cline { 3 - 5 } & & CNP average & BNP average & Total average \\
\hline 1 & Fasciola spp. & 550.00 & 350.00 & 450.00 \\
\hline 2 & Paramphistomum spp. & 650.00 & 550.00 & 600.00 \\
\hline 3 & Schistosoma spp. & 400.00 & 600.00 & 500.00 \\
\hline 4 & Dicrocoelium spp. & 900.00 & - & 900.00 \\
\hline 5 & Moniezia spp. & 700.00 & 433.30 & 566.65 \\
\hline 6 & Oesophagostomum spp. & 1400.00 & 650.00 & 1025.00 \\
\hline 7 & Chabertia spp. & 1233.30 & 1050.00 & 1141.65 \\
\hline 8 & Strongyloides spp. & 1966.67 & 1150.00 & 1558.34 \\
\hline 9 & Strongylus spp. & 1700.00 & 1700.00 & 1700.00 \\
\hline
\end{tabular}


Annex VIII: EPG count for different helminths parasites of wild Indian rhinoceros of CNP and BNP

\begin{tabular}{|c|l|c|c|c|}
\hline \multirow{2}{*}{ S.N. } & \multirow{2}{*}{ Helminth species } & \multicolumn{3}{|c|}{ EPG Average } \\
\cline { 2 - 4 } & & CNP average & BNP average & Total average \\
\hline 1 & Fasciola spp. & 366.67 & 350.00 & 358.34 \\
\hline 2 & Paramphistomum spp. & 550.00 & 500.00 & 525.00 \\
\hline 3 & Schistosoma spp. & 550.00 & 400.00 & 475.00 \\
\hline 4 & Moniezia spp. & 650.00 & - & 650.00 \\
\hline 5 & Strongyloides spp. & - & 1466.67 & 1466.67 \\
\hline 6 & Strongylus spp. & 1625.00 & - & 1625.00 \\
\hline 7 & Toxocara spp. & 733.33 & 666.67 & 700.00 \\
\hline 8 & Trychostrongylus spp. & 1166.67 & 1133.33 & 1150.00 \\
\hline
\end{tabular}

Annex IX: Prevalence based on the types of class of helminth in Wild Asian elephant and Indian rhinoceros

\begin{tabular}{|l|c|c|c|c|c|c|c|c|}
\hline & \multicolumn{4}{|c|}{ Wild Asian elephant } & \multicolumn{3}{c|}{ Wild Indian rhinoceros } & \\
\cline { 2 - 10 } & CNP & BNP & Total & $\%$ & CNP & BNP & Total & $\%$ \\
\hline Trematodes & 16 & 18 & 34 & 41.46 & 12 & 11 & 23 & 44.23 \\
\hline Nematodes & 17 & 19 & 36 & 43.90 & 12 & 13 & 25 & 48.08 \\
\hline Cestodes & 6 & 6 & 12 & 14.63 & 4 & 0 & 4 & 7.69 \\
\hline Total & 39 & 43 & 82 & 100 & 28 & 24 & 52 & 100 \\
\hline
\end{tabular}


Annex X: Photos of the different eggs of helminth

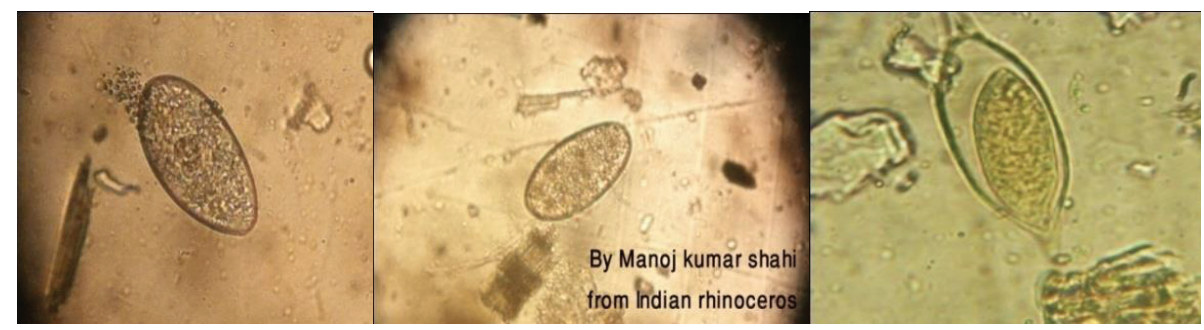

1: Fasciola spp. $\quad$ 2:Paramphistomum spp. $\quad 3:$ Schistosoma spp.

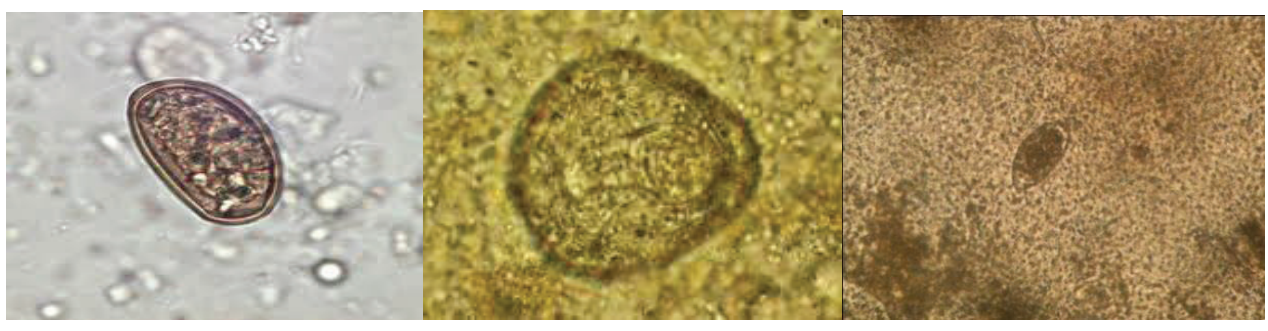

4: Dicrocoelium spp. $\quad$ 5: Moniezia spp. $\quad$ 6: Chabertia spp.

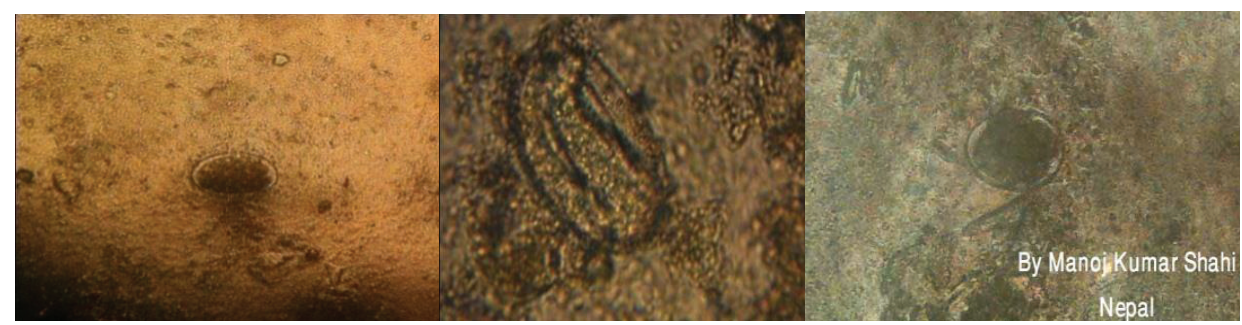

7: Oesophagostomum spp. $\quad$ 8:Strongyloides spp. $\quad$ 9: Strongylus 